\title{
KEBERTAHANAN KULTURAL DAN RELIGI DI AREA PERMUKIMAN TERDAMPAK BENCANA LUMPUR LAPINDO SIDOARJO, JAWA TIMUR
}

\author{
June Ekawati
}

Program Studi Teknik Sipil, Fakultas Teknik, Universitas Yos Soedarso Surabaya

Jl. Dukuh Kupang Barat I / 216-218 Surabaya, Indonesia

E-mail: juneekawati@unyos.ac.id

\section{Abstract \\ Cultural and Religion Resilience in Settlement Areas Affected by the Lapindo Sidoarjo Mudflow Disaster, East Java}

Indonesia is a disaster-prone country, therefore efforts for Disaster Risk Reduction are very useful to do.This paper aims to examine the cultural and religious roles of settlement in areas affected by the Lapindo mudflow disaster in Sidoarjo. The method used in this study is the study of relevant literature from research that has been done before. From the results of the literature review, it was concluded that culture and religion became capital for the people who were maintained even though their settlements were now scattered. Culture and religion also become identities which are very influential factors for the resilience of settlements which up to now still have vulnerability, so that anticipation and adaptation need to be carried out as preparedness for possible future disasters.

Key words: Disaster Risk Reduction, Cultural and Religion Resilience, Vulnerability, Preparedness

\section{Pendahuluan}

Secara global, semua kota di seluruh dunia rentan terhadap dampak bencana yang disebabkan oleh alam maupun manusia. Saat ini kejadian ben-cana di dunia mengalami peningkatan, dimana $76 \%$ adalah bencana hidrometeorologi (seperti banjir, longsor, siklon tropis, dan kekeringan). Dampaknya sebagian besar terjadi di negara-negara miskin dan sedang berkembang. Sementara kecenderungan yang terjadi adalah makin meningkatnya bencana karena pertumbuhan jumlah penduduk, urbanisasi,degradasi lingkungan, kemiskinan, dan pengaruh perubahan iklim global (Nugroho, 2013).

Indonesia yang letaknya secara geologis dan geografis berada pada ring of fire, banyak memiliki gunung berapi aktif sehingga sangat rawan memicu frekuensi terjadinya bencana alam, gempa dan letusan gunung berapi yang lebih banyak. Bahkan, banyak pihak menyatakan bahwa Indonesia adalah supermarket bencana, baik bencana banjir, tanah longsor, gempa bumi, gunung meletus maupun jenis bencana lainnya.

Sehubungan dengan masalah kejadian bencana ternyata semburan lumpur Lapindo di Sidoarjo adalah salah satu bencana yang pernah menyita banyak perhatian di Indonesia, bahkan dunia, yang sampai sekarang penanganannya masih belum optimal. Bencana ini sangat unik karena banyaknya perdebatan para pakar tentang penyebab terjadinya bencanaitu, apakah sebagai akibat dari kelalaian manusia atau bencana alam. Peristiwa keluarnya gas dan lumpur panas dari dalam tanah pada tanggal 29 Mei 2006 yang menggenangi dan menghancurkan kehidupan ribuan warga masyarakat di 17 desa pada 3 kecamatan di Kabupaten Sidoarjo (Jawa Timur) ini menjadi awal 
bencana yang masih terus menjadi ancaman hingga kini. Akibat bencana tersebut, masyarakat di area terdampak mengalami kerugian besar seperti kehilangan tanah, rumah, dan mata pencaharian, serta kerugian sosial ekonomi yang lebih besar. Bahkan mereka juga harus tercerabut dari akar sosio-historisnya karena terpaksa pindah dari tempat tinggal dan lingkungan sosial lama mereka.

Kebertahanan permukiman menjadi penting untuk menjadi fokus bahasan karena bencana semburan lumpur Lapindo ini terletak di daerah pemukiman padat penduduk, bahkan di beberapa titik merupakan kawasan perumahan (residence). Beberapa alasan lain adalah sebagai berikut (1) permukiman padat penduduk sangat rentan saat terkena bencana karena populasi yang padat akan banyak menjadi korban dari rusaknya struktur dan konstruksi bangunan; (2) posisinya sebagai pusat kegiatan ekonomi dan budaya; serta (3) lokasinya yang berada pada jalur utama penghubung (baik rel kereta api maupun jalan raya utama) antara kota-kota besar di bagian selatan dan timur Provinsi Jawa Timur ke Surabaya sebagai pusat perdagangan di Jawa Timur, bahkan Indonesia Bagian Timur.

Hingga saat ini, permukiman di sekitar tanggul Lapindo masih memiliki kerawanan bencana, sehingga antisipasi dan adaptasi perlu dilakukan sebagai kesiapsiagaan terhadap kemungkinan bencana di masa mendatang. Kesiapsiagaan ini akan memungkinkan permukiman yang ada bisa segera pulih kembali pasca bencana dan terus bertahan. Untuk itu, tujuan penelitian ini adalah mengkaji pentingnya kultural dan religi menjadi variabel dalam kebertahanan permukiman masyarakat. Adapun manfaatnya adalah 1) dapat memberikan masukan atau rekomendasi dalam pembuatan kebijakan sehingga dapat meminimalkan dampak bencana yang terjadi pada permukiman penduduk; 2) mempersingkat periode pemulihan terhadap dampak bencana agar masyarakat bisa segera beradaptasi dengan kondisi fisik yang ada saat ini; bahkan mampu meningkatkan kualitas lingkungan fisik, maupun aktivitas sosial, ekonomi, budaya dan religinya sehari-hari. Dari segi teoritis, penelitian ini diharapkan dapat mengembangkan teori tentang kebertahanan budaya dan religi di permukiman yang hasilnya dapat dipakai untuk proses resetlement masyarakat terdampak bencana berbasis budaya dan religi di lokasi lainnya. 




Gambar 1: Kerangka Pemikiran Masalah Penelitian(Sumber : Analisis Penulis, 2018)

\section{Kebertahanan dan Kerentanan (Vulnerability) terhadap Bencana}

Konsep Resilience yang digagaspadalevel internasional pada satu dekade terakhir ini merupakan pendekatan baru dan menjadi paradigma Pengurangan Resiko Bencana (PRB) atau Disaster Risk Reduction yang memberikan dampak positif karena dianggap mampu membawa perspektif baru dalam memahami ketahanan terhadap bencana, dengan memberikan arahan bagaimana sebuah kota, komunitas, infrastruktur, atau pun settlement bisa memiliki sebuah ketahanan untuk menghadapi berbagai resiko bencana (Rezki, 2011).

Kebertahanan (resilience) dalam kamus yang disusun oleh A.S. Hornby, et al (1956) diartikan sebagai "the quality or property of assuming the original shape after being pulled or press; elasticity; the power of recovering quickly". Beberapa definisi dari kebertahanan yang dikemukakan sebelumnya adalah dari Wildavsky yang merumuskan resilience sebagai konsep yang karakteristiknya adalah keragaman, efisiensi, otonomi, kekuatan, saling ketergantungan, adaptasi, dan kolaborasi. Sementara itu, Timmerman dan UNISDR (Timmerman, 1981; UNISDR, 2010) mendefinisikan resilience sebagai kemampuan atau kapasitas sistem untuk beradaptasi dan pulih dari terjadinya peristiwa yang berbahaya. IPCC, sebagaimana pendapat Cumming, melengkapi konsep kebertahanan sebagai kapasitas sistem sosial, ekonomi dan lingkungan untuk mengatasi peristiwa berbahaya, merespon atau mengorganisasi kembali dengan cara mempertahankan fungsi, identitas, struktur, kapasitas untuk 
adaptasi, belajar dan transformasi (IPCC, 2014). Namun Cumming menyebutkan tentang kemampuan sistem untuk menjaga identitasnyadalam menghadapi perubahan internal dan guncangan eksternal (Cumming, 2005).

Konsep Resilience diartikan sebagai kemampuan sistem sosial untuk merespon dan pulih dari bencana, termasuk kondisi melekat yang memungkinkan sistem untuk menyerap dampak serta mengatasinya saat dan pasca bencana, proses adaptasi yang memfasilitasi kemampuan sistem sosial untuk mengorganisasi kembali, mengubah, belajar merespon tantangan (Cutter, 2008). Sementara itu, Mayunga (2007) menyarankan suatu pendekatan berbasis kapital untuk mempelajari kebertahanandari bencana alam dengan mengemukakan lima bentuk kapital yang dapat berkontribusi dalam mengurangi vulnerability dan community resilience.

$$
\text { Rezki (2011) mengungkapkan }
$$
bahwa settlement resilience mencakup aspek fisik ataupun non fisik. Jika resilience pada infrastruktur lebih menekankan pada aspek fisik, dan community resilience menekankan pada aspek sosial, maka resilient settlement menekankan pada seluruh aspek yaitu legal, fisik, sosial, lingkungan, politik, dan ekonomi. Perencanaan resilient settlement adalah perencanaan yang komprehensif dan harus mempertimbangkan banyak aspek terkait sistem yang menyusunnya. Lebih lanjut, Pelling (2003) menyatakan bahwa jika aspek fisik, sosial, politik, ekonomi, insitusi, dan ekologi merupakan komponen yang menyusun dan saling mempengaruhi nilai vulnerability dan resilience, maka resilient settlement juga sangat dipengaruhi aspek-aspek tersebut, sebagaimana digambarkan secara grafis pada gambar 1.2.

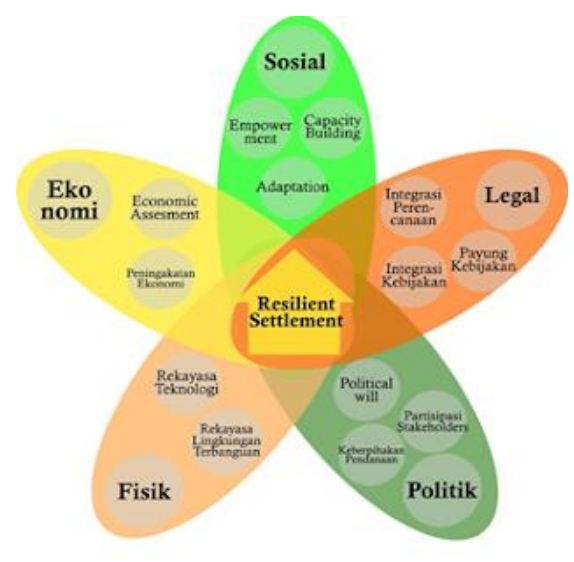

Gambar 2: Konsep Resilient Settlement (Sumber: Muhammad Rezki Hr, 2011)

Kerentanan (Vulnerability) juga merupakan konsep dalam paradigma Pengurangan Resiko Bencana (PRB), didefinisikan Djalante dan Frank (2010) sebagai suatu kondisi yang sangat rawan terhadap resiko bencana dan sangat dipengaruhi oleh faktor atau proses fisik, sosial, ekonomi dan lingkungan. Mengingatkonsep resilience dan kerentanan sangat erat hubungannya, maka faktor atau proses fisik, sosial, ekonomi dan lingkungan juga sangat mempengaruhi nilai-nilai resilience. Untuk mempermudah pemahaman mengenai konsep resilience, resilience juga bisa didefinisikan sebagai lawan dari kerentanan (vulnerability) terhadap resiko bencana. Mengurangi nilai kerentanan, berarti juga meningkatkan nilai resilience.

The United Nations Office for Disaster Risk Reduction mendiferensiasikan kerentanan fisik, sosial, ekonomi dan lingkungan dan mendefinisikan social vulnerability sebagai "ketidakmampuan orang, organisasi dan masyarakat untuk menahan dampak buruk bahaya dengan karakteristik yang melekat dalam interaksi sosial, institusi dan sistem nilai-nilai budaya. Ini terkait dengan tingkat kesejahteraan individu, komunitas, dan masyarakat, yang mencakup aspek-aspek yang berhubungan dengan tingkat literasi dan pendidikan, adanya perdamaian dan keamanan, akses kepada hak asasi manusia, 
sistem pemerintahan yang baik, keadilan sosial, nilai-nilai tradisional yang positif, adat-istiadat dan keyakinan ideologis serta sistem organisasi kolektif secara keseluruhan."

Sementara itu, adaptasi adalah sebuah respon yang dilakukan untuk mengantisipasi atau menghadapi perubahan. Dalam aspek sosial sistem settlement, adaptasi didefinisikan sebagai proses pembelajaran (baik itu oleh individual, kelompok, maupun komunitas sosial) dari sebuah pengalaman untuk mengantisipasi dan menghadapi perubahan kondisi alam, yang berfungsi untuk memberikan umpan balik, sehingga kedepannya bisa merubah dan meningkatkan kapasitas dalam praktek, kebijakan, dan pendekatan pada tataran settlement. Adaptasi tersebut pada gilirannnya akan menyebabkan terjadinya perbaikan nilai-nilai sosial dan budaya (DPCD Victoria 2008). Kemampuan adaptasi dalam komunitas settlement juga didefinisIkan sebagai kemampuan sistem untuk menyesuaikan diri dengan tekanan yang dihadapi (resiko bencana) dan untuk mengatasi konsekuensi yang tercipta dengan adanya tekanan tersebut (Rezki, 2011).

\section{Permukiman, Budaya dan Religi dalam Masyarakat}

Undang-Undang Republik Indonesia No. 1 Tahun 2011 tentang Perumahan dan Kawasan Permukiman, memberi pengertian bahwa permukiman adalah bagian dari lingkungan hunian yang terdiri atas lebih dari satu satuan perumahan yang mempunyai prasarana, sarana, utilitas umum, serta mempunyai penunjang kegiatan fungsi lain di kawasan perkotaan atau kawasan perdesaan. Secara utuh permukiman merupakan sebuah kegiatan dari sekelompok masyarakat yang tinggal dan berdiam pada suatu daerah dan melaksanakan berbagai aktifitas kehidupan serta kelangsungan hidupnya. Dalam konteks pembahasan yang terkait dengan konsep kerentanan dan resilience, maka DPCD Victoria (2008) dalam Rezki (2011) mendefinisikan settlement sebagai " $A$ discrete, relatively permanent group of households, most often with services, that together form a built-up environment or urban system". Discrete (ciri khas) yang dimaksud di siniadalah memiliki identitas tertentu yang tergantung pada tempat, waktu, dan budaya.

Doxiadis (1977) menyampaikan bahwa permukiman merupakan tempat dari sekelompok manusia yang hidup dan memiliki hubungan erat baik antar manusia itu sendiri maupun kelompoknya masyarakat lingkungan binaannya serta unsur-unsur buatan yang berlangsung di dalamnya. Dikatakan pula bahwa terdapat lima elemen yang membentuk permukiman dan saling berkaitan yang disebut dengan 'ekistics elements', yaitu (1) Alam, sebagai sebuah sistem; (2) Manusia, individu yang ada di dalam sistem tersebut; (3) Masyarakat; kelompok dari individu sebagai sebuah kehidupan sosial; (4) 'Shells', menyangkut semua hal yang terbangun, di mana manusia ada di dalamnya; (5) 'Networks' Jejaring, yaitu infrastruktur sebagai penghubung di dalam sistem. Teori itu menjelaskan bahwa unsur manusia dan keseimbangan lingkungannya menjadi obyek yang sama pentingnya diperhatikan dan dikenal sebagai antroposentris.

Masyarakat miskin perkotaan biasanya berada pada resiko tertinggi dalam hal bencana alam karena lokasi permukiman ditempati oleh masyarakat berpenghasilan rendah. Permukiman sering berlokasi di daerah rentan banjir dan tanah longsor, kurangnya infrastruktur, dan perumahan yang rentan terhadap kerusakan, kebakaran, resiko badai, banjir, tanah longsor, dan suhu ekstrim, cenderung mendapatkan distribusi yang tidak merata pada aset langka seperti air, pasokan energi, dan infrastruktur perkotaan sehingga 
meningkatkan kerentanan mereka (World Bank, 2008).

Rapoport (dalam Antariksa, 2011) menyatakan bahwa budaya sebagai suatukompleks gagasan dan pikiran manusia bersifat tidak terjaga. Kebudayaan ini akan terwujudmelalui pandangan hidup, tata nilai (values), gaya hidup (life style), dan aktifitas yang bersifat konkrit. Adapun pengelompokanpermukiman tidak selalu menghasilkan bentuk denah dan pola persebaran yangsama, tetapi tergantung pada latar belakang budaya yang ada. Lebih lanjut Rapoport (dalam Antariksa, 2011) juga mengemukakan bahwa permukiman tradisional merupakan manifestasi dari nilai sosial budaya masyarakat yang erat kaitannya dengan nilai sosial budaya penghuninya, yang dalam proses penyusunannya menggunakan dasar norma-norma tradisi.

Krempl (2006) dalam Fitrianto (2011) mengungkap tentang perencanaan kultural sebagai suatu alat pembangunan yang terdiri atas seni dan budaya sebagai pusat proses pembangunan yang dapat menciptakan pelaksanaan terbaik pada kerangka kerja berkelanjutan serta perencanaan strategis. Kebudayaan menjadi tema sentral pembangunan yang merepresentasikan mimpi, nilai-nilai, kepercayaan dan teknik komunikasi dalam masyarakat. Perencanaan kultural lebih melihat komunitas sebagai co-dwellers dalam satu rumah.

Adat adalah bagian dari kebudayaan. Menurut Koentjaraningrat (1984), wujud adat dapat dibagi dalam empat tingkat, yaitu 1) tingkat nilaibudaya, berakar dalam bagian emosional dari alam jiwa manusia; 2) tingkat normanorma, nilai-nilai budaya yang sudah terkaitpada peranan-peranan tertentu dari manusia dalam masyarakat; 3) tingkat hukum, sistem hukum baik hukum adat maupun hukum tertulis; dan 4) tingkat aturan khusus, mengaturaktifitas-aktifitas yang amat jelas dan terbatas ruang lingkupnya dalam kehidupan masyarakat.

\section{Kabupaten Sidoarjo}

Sebelum Belanda datang dan menjajah Indonesia, Surabaya (dan Pasuruan) yang posisinya strategis di tengah kepulauan nusantara, telah dikenal dunia sebagai kota pelabuhan yang besar. Posisi strategis Surabaya waktu itu membawa keuntungan bagi kawasan pendukungnya (hinterlands), termasuk Sidoarjo.

Untuk mendukung posisi Surabaya sebagai pintu utama keluar danmasuknya komoditi, pemerintah Kolonial Belanda membangun dua kawasan industri besar di sekitar Surabaya yang diberi nama SIER (Surabaya Industrial Estate Rungkut) di kawasan Surabaya selatan dan PIER (Pasuruan Industrial Estate Rembang) di Pasuruan sekitar 1,5 jam perjalanan ke arah selatan-timur Surabaya melewati Sidoarjo. Pembangunan infrastruktur transportasi darat dan udara, seperti jalan tol, jalan raya, bandara dan terminal bus, mendukung Sidoarjo sebagai kota satelit utama Surabaya. Sementara itu, bandar udara internasional Juanda juga terletak di wilayah Sidoarjo. Demikian pula dengan terminal bus antar-kota Surabaya, juga berlokasi di wilayah Sidoarjo.

Proyek nasional jalan tol di Jawa Timur yang menghubungkan Surabaya dengan Gempol dan kota-kota di Jawa Timur bagian Timur (Pasuruan, Jember, dan Banyuwangi) dan Bali dengan kotakota di bagian Selatan (Pandaan, Batu, dan Malang). Sidoarjo, yang terletak di antara Surabaya dan Gempol, mendapatkan kemudahan transportasi menuju/dari Surabaya. Jalan tol Surabaya-Gempol yang menjadi tulang punggung (backbone) transportasi di Jawa Timur, kemudian putus akibat bencana lumpur Lapindo sehingga berdampak signifikan bagi perekonomian Jawa Timur. 
Sebelum tumbuh dan berkembangnya Sidoarjo sebagai kawasan industri, mayoritas penduduk di kawasan yang terkena lumpur Lapindo (Porong Sidoarjo) ini bekerja di sektor pertanian sebagai petani dan buruh tani. Selain itu, mereka juga memiliki tambahanpenghasilan sebagai pedagang hasil bumi, beternak, dan menjadipengrajin. Kegiatan semacam itu terus menerus dilakukan secara turun temurun oleh banyakkeluarga di daerah itu. Perlahan-lahan, kondisi ini berubah akibat munculnya beberapa pabrik di wilayah tersebut yang ternyata membutuhkan tenaga kerja untuk dipekerjakan sebagai buruh pabrik. Warga pun mulai beralih profesi dari petanimenjadi buruh industri. Sektor industri di Porong Sidoarjo berkembang pesat karena lokasinya yang berdekatan denganpusat bisnis kawasan Indonesia Timur (Surabaya), Pelabuhan Tanjung Perak dan Bandar Udara Juanda, serta memiliki sumber daya manusia yang produktif serta kondisi sosial politik dankeamanan yang relatif stabil sehingga menarik minat investor untuk menanamkan modalnya (Daulay \& Sumarmi, 2009).

\subsection{Bencana Lumpur Lapindo}

Sejak tanggal 29 Mei 2006, terjadi bencana semburan gas dan lumpur di dekat sumur eksplorasi Banjarpanji-1, di Desa Reno Kenongo, Kecamatan Porong,
Kabupaten Sidoarjo, Jawa Timur, yang hingga kini belum tuntas. Lumpur panas yang menyembur volumenya mencapai $100.000-150.000 \mathrm{~m}^{3}$ per hari (Batubara, 2012), namun berdasarkan laporan forum international AAPG 28 Oktober 2008 di Cape Town, Afrika Selatan, disebutkan bahwa antara tahun 2006 sampai Juli 2007 volume semburan berkisar antara 120.000 $180.000 \mathrm{~m}^{3}$ per hari.

Luapan lumpur Lapindo ini telah menggenangi wilayah lebih dari $6,5 \mathrm{Km} 2$ termasuk kawasan industri, areal pertanian, dan jalan tol Surabaya-Gempol, permukiman padat penduduk, bahkan di beberapa titik merupakan kawasan perumahan (residence). Adapun desa yang tergenang diantaranya adalah Reno Kenongo, Siring (bagian timur), Jatirejo (bagian timur), Glagaharum (bagian barat), Kedungbendo, Ketapang (bagian timur), dan Besuki (bagian barat) yang terletak di wilayah administrasi tiga kecamatan, yaitu Tanggulangin, Porong, dan Jabon.

Bencana ini membawa dampak luar biasa bagi masyarakat sekitar dan bagi aktivitas perekonomian di Jawa Timur (Batubara, 2012), kerugian pada infrastruktur dan lingkungan di sekitarnya, tetapi juga kerugian harta benda masyarakat. Total warga yang dievakuasi lebih dari 8.200 jiwa dan korban jiwa.

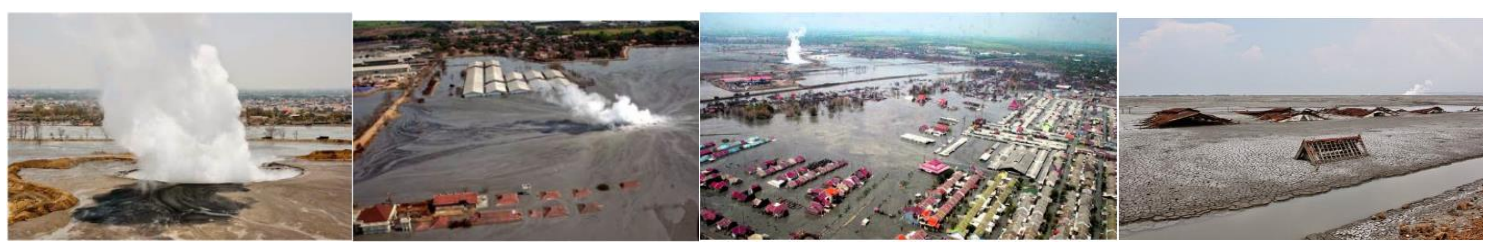

Gambar 3: Dampak Semburan Lumpur Panas Lapindo terhadap Lingkungan Sekitarnya (Sumber: http://pr-sekolahku.blogspot.com/2015/02/artikel-bencana-lumpur-lapindo.html)

\section{2. Kondisi Pasca Bencana Lumpur Lapindo}

Sebelum terjadi bencana, kawasan tersebut merupakan kawasan industri yang menjadi sumber pekerjaan bagi warga sekitar maupun warga luar kota. Kerugian yang dialami adalah kehilangan aset infrastruktur, sektor industri di Sidoarjo, dan dampak secara tidak langsung pada sektor ekonomi Provinsi Jawa Timur 
khususnya sektor makanan, kerajinan kulit di Tanggulangin yang omsetnya menurun.

Pada bagian timur dari luapan lumpur Lapindo merupakan kawasan pertambakan sebagai tempat budidaya ikan di Kabupaten Sidoarjo yang merupakan

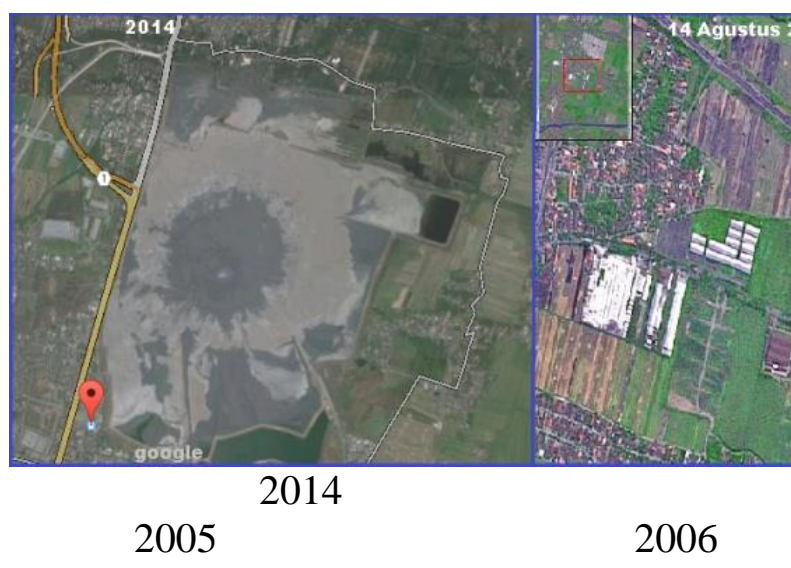

Gambar 4: Foto Udara Area Terdampak Sebelum dan Sesudah Bencana Lumpur Lapindo (Sumber :https://thephenomena.files.wordpress.com/ 2014/09/porong lumpur_lapindo_sebelum dan_sesudah.png)

\section{Analisis}

\subsection{Kerentanan Permukiman}

Luapan lumpur Lapindo di Porong Sidoarjo, selain mengakibatkan ribuan warga kehilangan tempat tinggal, juga itu menenggelamkan nilai-nilai sosial budaya, serta situs-situs kerajaan Majapahit yang diperkirakan berada di wilayah tersebut (Aribowo, 2010). Banyak situs-situs yang diduga berupa candi-candi berada di bawah luapan lumpur Lapindo. Dikatakan pula bahwa situs atau candi-candi itu merupakan peninggalan zaman kerajaan Majapahit yang juga dikenal sebagai kerajaan maritim. Sidoarjo dinamakan Kota Delta karena ada pertemuan antara dua sungai sehingga banyak situs-situs zaman kerajaan Majapahit. Majapahit di Mojokerto merupakan kerajaan maritim yang memiliki pengaruh sampai ke sungai Kalimas Surabaya dan ke Sidoarjo. Jika asumsi itu produk unggulan dalam bidang perikanan. Akibat pencemaran lumpur Lapindo mengakibatkan kematian budidaya udang, sehingga petani mengalami kerugian sangat besar.

benar, maka pada waktu di sepanjang Sidoarjo termasuk di Porong, merupakan aktifitas pemerintahan.

Sebenarnya Sidoarjo bukan termasuk daerah yang rawan bencana. Namun fenomena bencana semburan lumpur Lapindo yang begitu besar dampaknya ini akhirnya membalikkan fakta yang ada. Masyarakat, termasuk struktur pemerintah daerah tidak memiliki kesiapsiagaan dalam manajemen bencana. Hingga tahun 2018 kerentanan permukiman di sana terdampak masih sangat tinggi. Perluasan tanggul penahan lumpur yang telah dibangun beberapa kali mengalami perluasan. Desa yang sebelumnya tergolong memiliki kerentanan tinggi, ternyata justru tenggelam. Beberapa wilayah desa juga tenggelam sebagian.

Bencana semburan lumpur ini juga mengakibatkan kerusakan infrastruktur yang sudah ada di sekitar lokasi semburan diantaranya adalah turunnya permukaan jalan arteri di Porong, bengkoknya rel kereta api, pecahnya pipa PADM, pecahnya pipa Pertamina, danputusnya jembatan jalan tol. Dampak lainyanya adalah amblesnya tanggul penahan lumpuryang berada di sekitar pusat semburan, yang disebut dengan tanggul cincin, juga tanggulluar untuk menahan luapan lumpur di sekitar area terdampak (Agustawijaya, 2017)

Kerentanan permukiman juga dapat terlihat dari retakan pada dinding-dinding rumah warga, land subsidence dan uplift, keruhnya air tanah, bau yang menyengat,serta gas yang masih terus keluar dari perut bumi. Kondisi kerentananmembuat masyarakat masih harus memiliki kesiapsiagaan tinggi untuk mengantisipasi kejadian bencana yang tidak diharapkan. Hal ini tentunya dimaksudkan agar dapat meminimalkan dampak bencana 
yang akan menimpa permukiman masyarakat serta mempercepat proses pemulihan maupun adaptasi terhadap kerentanan yang ada.

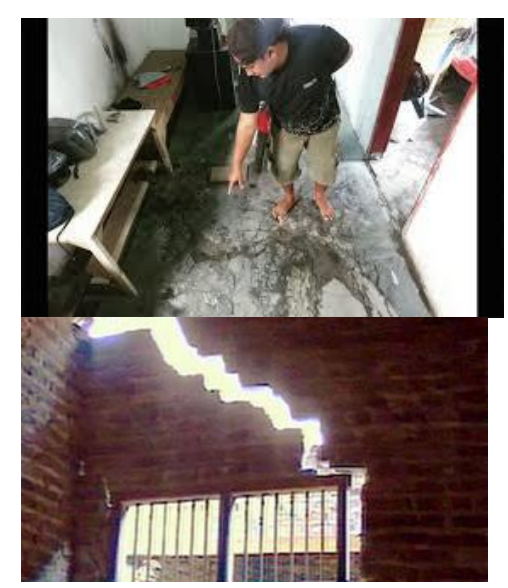

Gambar 5: Kondisi retak-retak pada dinding dan lantai rumah warga di Desa Renokenongo dan Tanggulangin (Sumber : https://www.google.co.id/ search?q=gambar+rumah+retak+lapindo\&s afe )

\section{2. Kebertahanan Sosial, Budaya dan Religi Masyarakat}

Pasca bencana, masyarakat di area terdampak bencana harus mencari lokasi permukiman di lokasi yang terpencar. Pada peristiwa bencana itu,permukiman korban yang sebagian besar adalah warga kecamatan Porong mengalami kerusakan dan/atau kehilangan fisik yang mengganggu rutinitas sehari-hari mereka. Lumpur panas merupakan fenonema alam yang konkret ada secara fisik dan kehadirannya itu mengganggu aktivitas dan fungsi-fungsi rutin dalam suatu komunitas.

Kejadian bencanaini menjadi momentum yang mengikat solidaritas dalam masyarakat, yaitu dengan adanya pembentukan kelompok-kelompok sosial yang mengorganisir korban untuk mendapatkan kompensasi dan menyiratkan kuatnya solidaritas korban dalam menghadapi masalah bencana. Pada sisi lain bencana diyakini juga dapat memicu munculnya konflik sosial, yaitu terpecahpecahnya masyarakat dalam kelompokkelompok sosial baru. Rekonstruksi identitas untuk keberlanjutan korban bencana lumpur Lapindo ternyata butuh perjuangan panjang, namun kehilangan teritori dan permukiman yang terpencar tidaklah mengurangi identitas sosial mereka (Farida, 2014).

Upaya relokasi bagi masyarakat terdampak lumpur Lapindo sebenarnya bukan perkara mudah. Dalam konteks ini, relokasi bukan hanya sekedar perpindahan rumah secara fisik-geografis, tetapi ini adalah proses sosial budaya bahkan ekonomi (Iftita dan Zurinani, 2017). Lingkungan sosial masyarakat yang di dalamnya terdapat jaringan-jaringan sosial merupakan salah satu sumber daya yang penting ketika terjadi bencana. Ruangruang komunal seperti lokasi pengungsian di Pasar Baru Porong dan mushollamusholla menjadi tempat berkumpul yang memudahkan korban berkomunikasi dan berkoordinasi untuk membicarakan hal-hal penting. Kemampuan adaptasi dalam komunitas settlement atau kemampuan sistem untuk menyesuaikan diri dengan tekanan yang dihadapi (dampak bencana) dan untuk mengatasi konsekuensi yang tercipta dengan adanya tekanan tersebut, benar-benar diuji pasca bencana. Dengan adanya ikatan sosial yang baik antar warga memunculkan paguyuban yang menaungi anggotanya merupakan sumber daya sosial (Social Resources) bagi kebertahanan yang memiliki peran penting dalam proses pemulihan anggotanya.

Hal menarik lainnya adalah terkait dengan budaya dan religi masyarakat di area terdampak bencana, dapat dijumpai pada aktivitas istighosah dan nyekar yang diadakan masyarakat di tepi tanggul lumpur Lapindo (lihat Gambar 6). Anggota masyarakat yang telah bermukim terpencar tetap hadir dan berkumpul bersama untuk berdoa di makam-makam kerabat dan leluhur mereka yang ikut terendam lumpur. Aktivitas yang diagendakan secara rutin 
oleh masyarakat yaitu 'nyekar' di tepi tanggul karena makam orang tua dan kerabat mereka terendam lumpur, diawali dengan istighosah bersama dan dihadiri oleh warga dan korban yang saat ini sudah tercerai-berai menghuni lokasi permukiman di lokasi lain.Aktivitas ini biasanya diadakan setiap tahun menjelang Idul Fitri.

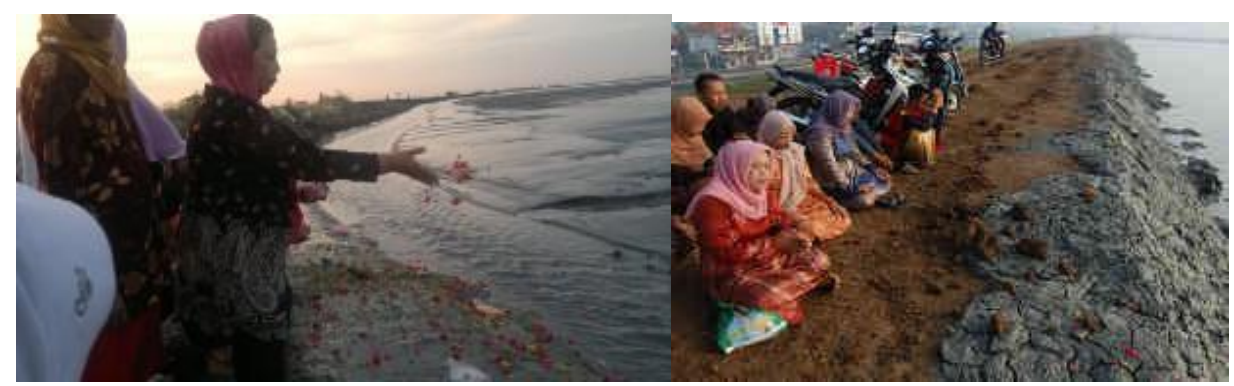

Gambar 6: Prosesi "Nyekar" masyarakat korban Bencana Lumpur Lapindo(Sumber https://news.detik.com/berita-jawa-timur/d-1438736/usai-salat-id-korban-lumpur-lapindonyekar-di-atas-tanggul )

Menurut Yamuna Kaluarachchi (2018) yang meneliti beberapa kasus di Nepal, untuk resettlement korban bencana perlu mempertimbangkan etnisitas, budaya, maupun religi dari masyarakatnya. Bahkan Dasai (2017) mengemukakan tentang cultural resilient dengan mengambil kasus permukiman etnis Jawa di Suriname, walaupun kasusnya agak berbeda karena kebertahanan permukiman pasca bencana. Yang menarik, ternyata budaya Jawa masih tetap bertahan dan melekat sebagai identitas walaupun masyarakatnya sudah tidak lagi berada di tanah nenek moyangnya di Pulau Jawa.

Sebagaimana yang dikemukakan oleh Rapoport (dalam Antariksa, 2011), permukiman tradisional merupakan manifestasi dari nilai sosial budaya masyarakat yang erat kaitannya dengan nilai-nilai sosial budaya penghuninya, yang dalam proses penyusunannya menggunakan dasar norma-norma tradisi setempat. Tradisi "nyekar" merupakan manifestasi dari nilai sosial, budaya dan religi masyarakat yang sudah menjadi identitas dalam kehidupan di lingkungan permukiman mereka. Bahkan ketika terjadi bencana semburan Lumpur Lapindo yang menyebabkan warga masyarakat kehilangan permukimannya secara fisik dan terpaksa pindah ke lokasi lain. Aktivitas budaya dan religi ini tetap bertahan sebagai tradisi yang merupakan suatu bentuk penghormatan kepada kerabat dan leluhur yang terkubur bersama permukiman mereka. Kolam lumpur sudah menjadi ruang komunal bagi masyarakat untuk bernostalgia, berkumpul kembali dan mengenang histori asal-usul leluhur mereka.

Prosesi "nyekar" di lokasi tersebut merupakan suatu ritual keagamaan yang sudah mentradisi atau membudaya dalam kehidupan masyarakat di area permukiman terdampak bencana lumpur lapindo ini. Dari rutinitas masyarakat ini didapatkan kesimpulan bahwa faktor kulturaldanreligi sangat berpengaruh dan menjadi modal kuat (cultural and religion resources) terhadap kebertahanan masyarakat yang kemudian pulih kembali pasca bencana. Tradisi yang menjadi aktivitas rutin masyarakat ini sudah merupakan adat istiadat bagian dari kebudayaan, dimana adat tersebut sesuai Koentjaraningrat (1984) berada pada tingkat nilai-budaya yang berakar dalam bagian emosionaldari alam jiwa manusia.

\section{Simpulan}

Indonesia adalah negara di dunia dengan potensi bencana yang sangat tinggi sehingga konsep kebertahanan sebagai paradigma dari pengurangan resiko bencana sangat diperlukan dan akan bermanfaat. Di 
samping itu fokusnya penyebab bancana juga memiliki keunikan tersendiri karena masih terus menjadi bahan perdebatan para pakar dalam hal status kebencanaannya, apakah termasuk bencana alam ataukah karena kelalaian manusia.

Kondisi kerentanan permukiman di area terdampak bencana lumpur Lapindo hingga 2018 masih tinggi sehingga masyarakat tetap perlu memiliki kesiapsiagaan secara terus menerus untuk mengantisipasi kejadian bencana yang tidak diharapkan. Hal ini tentunya dimaksudkan

\section{Daftar Pustaka}

Agustawijaya, Didi S. 2017. Analisis Risiko Bencana Berbasis GIS: Contoh Kasus Bencana Semburan Lumpur di Sidoarjo, University of Mataram, https://www.researchgate.net/ publication/320943953

Aribowo 2010. Seminar Refleksi 4 tahun Lapindo, Surabaya,29 April 2010, https://news.detik.com/berita-jawatimur/d-1347899/sosial-budayakesenian-dan-situs-kerajaan-ditelanlumpur, diakses 25/11/2018

Batubara, B. \& P. W. Utomo. 2012. Kronik Lumpur Lapindo, Skandal Bencana Industri Pemboran Migas di Sidoarjo. Yogyakarta: Insist Pers

Cutter, Susan L. et al 2014. The geographies of community disaster resilience, Global Environmental Change 29 2014, 65-77, http://www.sciencedirect.com/science/a rticle/pii/S0959378014001459.

Dasai, Marciano 2017. Emerging Cultural Resilient Settlements, International Journal of Inovatitive Research and Development, Vol 6 Issue 11, November, 2017, www.ijird.com, DOI agar dapat meminimalkan dampak bencana di masa mendatang.

Faktor sosial, budaya dan religi sangat berpengaruh dan menjadi modal kuat terhadap kebertahanan masyarakat yang pada akhirnya pulih kembali pasca bencana. Hal ini dapat dijumpai pada aktivitas istighosah dan nyekar yang setiap tahun rutin diadakan masyarakat di tepi tanggul lumpur Lapindo serta kuatnya solidaritas korban dalam menghadapi masalah bencana yang terjadi.

No.: 10.24940/ijird/2017/v6/i11/ NOV17086

Daulay, Pardamean \& Mamik Sumarmi. 2009. Survival Mechanism Victim Houshold of Lumpur Lapindo in Sidoarjo-Jawa Timur. Jurnal Organisasi dan Manajemen, Volume 6, Nomor 1, Maret 2010, 74-88, UPBJJUT Surabaya

Davies, R, et. al. 2007. Birth of a mud volcano: East Java. GSA Today, 29 May, p.4-9

Djalante, Riyanti dan Frank Thomalla 2010. Community Resilience To Natural Hazards And Climate Change Impacts: A Review Of Definitions And Operational Frameworks,

Doxiadis C.A. 1977. Ecology and Ekistics. Colorado: Westview Press. Boulder.

Elika, Elmaghfira Putri, dkk 2017. Bencana Sosial Kasus Lumpur PT. Lapindo Brantas Sidoarjo, Jawa Timur, Jurnal Penelitian \& PKM Universitas Padjajaran, Juli 2017 Vol 4, No: 2 Hal: $129-389$

Farida, Anis 2014. Reconstructing Social Identity for Sustainable Future of 
Lumpur Lapindo Victims, 4th International Conference on Sustainable Future for Human Security, SustaiN 2013, ScienceDirect, Procedia Environmental Sciences 20 ( 2014 ) 468 - 476, doi: 10.1016/j.proenv.2014.03.059, WWW.sciencedirect.com

Fauzan, A.U dan Batubara. 2010. Displacement and Changing Gender and Intergenerational Relations: Experience of Hot Mudflow Affected Families in East Java, Indonesia, International Conference on Economic Stress, Human Capital, and Families in Asia: Research and Policy Challenges, (hal. 1-11). Singapore.

Hornby, A. S. et al. 1956, The Advanced Learner's Dictionary of Current English, Oxford University Press, London.

Humaida, Hanik dkk. 2010, Semburan gas dan dampaknya terhadap lingkungan di sekitar Lumpur Sidoarjo, Jurnal Lingkungan dan Bencana Geologi, Vol. 1 No. 1 April 2010:43-58.

Iftita, Miftakhul \& Siti Zurinani (2017) Penyintas di Lumpur Tanpa Batas: Potret Pemulihan Sosial Ekonomi Masyarakat Terdampak Bencana Lumpur Lapindo, Endogami: Jurnal Ilmiah Kajian Antropologi, Program Studi Antropologi, Fakultas Ilmu Budaya Universitas Brawijaya, Malang.

IPCC 2014.

http://www.ipcc.ch/pdf/assessmentreport/ar5/wg2/WGIIAR5AnnexII_FINAL.pdfdiakses 9/11/2018.

Kaluarachchi, Yamuna. 2018. Building Community Resilience in the Resettlement of Displaced
Communities, 7th International Conference on Building Resilience; Using scientific knowledge to inform policy and practice in disaster risk reduction, ICBR2017, 27 - 29 November 2017, Bangkok, Thailand, Procedia Engineering 212 (2018) 443450

Koentjaraningrat 1984. Bunga Rampai Kebudayaan, Mentalitas dan Pembangunan. Jakarta: Gramedia.

Krempl. 2006. dalam Fitrianto, Achmad Room 2011. Cultural Planning as a Solution at Displacement and Recovery Problem in the Porong Mud Volcano Disaster, Journal of US-China Public Administration, November 2011, Vol. 8, No. 11, 1227-1241.

Mayunga, J. S. 2007, Understanding and applying the concept of community disaster resilience : acapital-based approach, A draft working paperprepared for the summer academy for social vulnerability and resilience building, Munich, Germany, 22-28 July2007.

Nugroho, Sutopo Purwo. 2016. Manajemen Bencana di Indonesia, Badan Nasional Penanggulangan Bencana

Rezki, Muhammad Hr. 2011. Resilient Settlement,

http://muhammadrezkihr.blogspot .com/2011/12/resilient-settlement.html. Diakses tanggal19/10/2018

Timmerman, Peter. 1981. Vulnerability, Resilience, and Collapse of Society, Institute for Environmental Studies, University of Toronto, Canada, http://www.ilankelman.org/miscellany/ Timmerman1981.pdf diaksses $\underline{14 / 11 / 2018}$ 
UNISDR. Urban Risk Reduction and Resilience, file:///E:/RESILIENT\%20SE TTLEMENT/ 37966_finalwp3unisdr.pdfdiakses 13/11/2018.

Vale, L. J. dan T. J. Campanella. 2005. The Resilience City: How Modern Cities Recover from Disaster. Oxford Univesity Press.

UN Habitat. Resilience 17 maret, 2014, https://unhabitat.org/tag/disaster-riskreduction/Resilience, diakses 9/11/2018.

Undang-Undang Republik Indonesia No. 1 Tahun 2011 tentang Perumahan dan Kawasan Permukiman. https://thephenomena.files.wordpress.com $/ 2$ 014/09/porong_lumpur_lapindo_sebelu m_dan_sesudah.pnghttps://news.detik.co m/berita-jawa-timur/d-1438736/usaisalat-id-korban-lumpur-lapindo-nyekardi-atas-tanggul diakses 9/11/2018

https://news.detik.com/berita-jawatimur/2296103/warga-korban-lumpurlapindo-nyekar-di-kolam-lumpur diakses 9/11/2018.

https://www.google.co.id/search?q=gambar +rumah+retak+lapindo\&safe diakses 28/11/2018. 